\title{
Safe City Strategy and Anti-terrorist Security Check in China's Public Transport*
}

\author{
Gang Luo \\ Law School \\ Xinjiang University \\ Urumqi, China 830046
}

\begin{abstract}
Cases of violence and terrorism happened in subways of Russia and Europe indicate terrorist attack in public transport is severely threatening urban public security and challenges the safe city strategy, the core topic of which is bound to be Anti-terrorist. We must determine the core of safe city again and transform from the hazard prevention in the traditional meaning to the terrorism prevention. The safe city strategy with preventive security check as major measures faces problems between efficiency and security, human rights and security. The construction of safe city in China is also threatened by terrorist attack. Problems must be solved through strengthen citizens' consensus on Anti-terrorist and improving the legalization degree of Anti-terrorist security check.
\end{abstract}

\section{Keywords-Anti-terrorist; public traffic; security check}

\section{INTRODUCTION}

In Apr.3, 2017, subway bombing attack happened suddenly in St. Petersburg, the second largest city of Russia, with thirteen people killed and nearly fifty people wounded. It triggers the concern of international society for security issue in urban public transport. According to the analysis on terrorist attacks happened in Europe in the past more than ten years, it is found that terrorists have paid special attention to urban public transport field. It means developed cities in the world have entered the period with dense terrorist attack. Meanwhile, it causes unprecedented challenge and impact on safe city strategy in the world.

\section{CONNOTATION AND VALUE OF SAFE City STRATEGY}

Safe city refers to the regional social community that has ability of effective resistance for natural disasters and social emergencies, maintains dynamic balance and coordinated development in environment, society and personal health and provides good order, comfortable living space and personal safety for urban citizens. 1

Undoubtedly, the proposition of safe city strategy has

*This paper is the phased research result of project supported by National Social Science Foundation in 2016 host by me, "Research on Anti-terrorist Mechanism in Urban Public Transport Field of Xinjiang" (Project No.: 16XFX008), and the important project of key research base of liberal arts in colleges of Xinjiang Uygur Autonomous Region, "Research on Anti-terrorist Mechanism in Urban Public Transport Field of Xinjiang" (Project No.: XJEDU010915A01 significance and symbolizes the urban management and development has entered a new period. The emphases of security strategy differ in different urban development periods. In initial stage of urban development, the primary threat is natural disasters and simple man-power disasters The countermeasure research focuses on general prevention and reduction of natural disasters. With social progress and economic development, urban population grows rapidly. The city functions change and unsafe factors increase in cities. Factors causing disasters expand continuously. The research field of urban safety expands to disaster prevention, public security and defense. After the new century, the influence of human activities on cities highlights, and problems of urban safety are complicated. On one hand, with constant improvement of functions and facilities of human settlements, the relations among human, nature and environment become increasingly complicated, and factors threatening cities increase; on the other hand, active market economy and increasing population movement cause diversified social issues. The influence of human factors on cities unceasingly highlights and strengthens, forming the unprecedented destroy. 2 In reality, with ceaseless urban development, the gathering of human, economy and culture and the diversification of urban social structure and space structure breed crime problems in cities. It has become an international tendency that crimes draw close in cities. 3

\section{TRANSFORMATION OF SAFE City STRATEGY ON THE BASIS OF ANTI-TERRORIST CONSCIOUSNESS}

Terrorism has boomed worldwide since "9.11" terrorist incident. Crime of terrorist activities increasingly replaces common criminal cases like steal and robbery, becoming the major source that influences the sense of safety of the pubic.

To pursue dramatic performance effect, terrorists often attack in public transport space with dense population and strong mobility, directly causing major casualties and property loss and severely disturbing normal life order in society. For example, in the terrorist attack happened in subway of Belgium in 2016, after the attack, railway and aviation systems as well as public transport system in the city are closed urgently. Suggestion given by officials for the public is to stay indoors. In this way, although the terrorist attack is over, the public transport system in the city is disturbed and damaged, and the daily work and life of 
citizens also stagnate. It is an unacceptable cruel fact in modern society with rapid development.

The reason why terrorist attack happens frequently in public transport field closely relates to the open public traffic pattern followed in European cities. In most European countries, in consideration of improving transport efficiency and humanization, subway security check only relies on monitor camera and a few inspectors. The open public transport pattern has obvious security flaw and is very frail. Therefore, safe city strategy must be transformed timely to prevent terrorist attack. The normal and strict preventive security check is necessary.

\section{THE PREVENTIVE ANTI-TERRORIST SECURITY CHECK IN SAFE City StRATEgy FACES Two PROBLEMS}

Although we have realized it is necessary to change the open public transport pattern and establish preventive system under the current situation with frequent terrorist activities, this is not easy because it means designing the whole public transport system again and requires enormous transformation cost. The deeper reason is that the overall implementation of preventive security check faces predicaments in transportation efficiency and protection of human rights.

\section{A. Predicament in Efficiency of Anti-terrorist Preventive Security Check}

The idea of pursuing liberty and convenience formed in a long time makes supporters of urban efficiency theory think the implementation of delicate and complicated preventive security check measures in places of public transport in modern cities with high-speed development can only cause paralysis of public transport. Excessive security check measures inevitably cause inconvenience for the public. 4 Therefore, the transportation planning in European cities values the rapid evacuation of the crowd. Except for the airport, railway station and subway station adopt open space design without any mandatory security check procedure.

In comparison, after the "9.11" terrorist attack, the American urban safety is prior to efficiency. The preventive security check in public transport field is very common. Although the excessively complicated preventive security check is criticized by scholars, most Americans have realized the abandon of some efficiency can better maintain security of the whole city. They understand and cooperate and accept the convenience brought by preventive security check has become a part of their daily life. 5 When European countries frequently face terrorist attacks, America can effective prevent and reduce extreme terrorist attack. We must acknowledge the attitudes of the public toward preventive security check play a vital role in it.

All in all, efficiency and security are dynamic contradiction in need of balance. Nowadays, terrorist activities are increasingly rampant. Obviously, we need to distribute the proportion of them. The public should change safety awareness and realize the safety first will inevitably reduce efficiency. Otherwise, we cannot effectively improve the density and strength of security check in public transport place and will fail to prevent the malicious terrorist attack.

\section{B. Predicament in Human Rights of Anti-terrorist Preventive Security Check}

Compared with entanglement of efficiency, the conflict and balance of liberty and security is the common problem in Anti-terrorist.

After the "9.11" event, many countries strengthen the preventive security check measures of Anti-terrorist in public transport field. The public often denounce it is suspected of violating human rights: First, Anti-terrorist security check means with application of high technology may involve privacy infringement. The most typical example is that the use of "whole-body scanner" triggers violent controversy; second, because of the difference of Anti-terrorist resources and the threatened degree, it is impossible to apply the same Anti-terrorist configuration to all places. 6 Therefore, in practice, preventive security check is applied to monitor areas of key defense in cities to seek more reasonable Antiterrorist resources and establishment of more effective urban Anti-terrorist system. In determination of key areas, the public transport field near Muslim's community is mainly monitored. And the strength of preventive security check measures in these places is higher than other places. However, it causes discrimination problems even problems of human rights. Therefore, many scholars criticize the country continuously infringes civil liberty on the excuse of Anti-terrorist. They think the security brought by infringement of liberty is delusive. Although it is for the sake of security, they cannot directly implement high-strength preventive security check measures without consideration of the requirement of human rights.

People holding the opposite view think in order to prevent Anti-terrorist attack, the urban safety precautions must be stricter. Constitutional scholar Posner observes the strict abidance of civil liberty and protection of human rights are under the premise of facing common criminals in society. It should be changed correspondingly with the change of the times. It is fatal if we still mechanically follow the outdated principles in face of the severe terrorist attack. In other words, people valuing human rights fail to seriously treat new characteristics and means of terrorist activities at present, so they improperly doubt the urgency of national security proposed by the government.

The two different opinions make European countries pause and ponder on implementation of preventive security check in public transport field and cause hidden danger. These countries become the best target of terrorist attack so that terrorist attack happens in these places frequently.

\section{ENLIGHTENMENT ON SAFE CITY STRATEGY OF CHINA}

In order to get out of the Anti-terrorist security predicament in urban public transport of foreign countries, we need to seriously clarify and actively resolve conflicts among liberty, efficiency and security, construct and improve the safe city strategy in consideration of different demands, and reach social consensus on Anti-terrorist and insist the appropriateness, necessity and effectiveness of Anti-terrorist security check. 


\section{A. Strengthen Consciousness of the Public on Anti-terrorist Security Check in Public Transport}

It is proposed on the Eighteenth National Congress of the CPC to accelerate the construction of urbanization. The urban transportation of China develops rapidly. Public transportation projects like subway and BRT appear in cities. Urban safety centering on pubic transport will be the core topic of China's safe city strategy. As the front line of Antiterrorist, Xinjiang region is constructing transport infrastructure and subway project in Silk Road Economic Belt. The safe city strategy has significance on social stability and economic development. However, more strenuous efforts are required to reach Anti-terrorist consensus because of the diversification and difference of religion, culture and custom. Firstly, correctly guide the public to correct regard the relation between security and efficiency, security and liberty. At present, it is necessary to properly abandon some efficiency and liberty because the security situation is increasingly severe. Liberty without security is not true liberty and will cause sense of fear and anxiety. Guarantee without security cannot reach the true efficiency. The construction of safe city must transform from "prior popular will" to "mass participation". Citizens should realize the construction of safe city is not only the responsibility of the police but also the responsibility and obligation of each citizen. 8 Secondly, government should not excessively reduce efficiency in taking safety measures. From the perspective of legislation strategy, the implementation of a standardizing system must improve people's consciousness of following the law. When imposing restrictions, it is also necessary to reduce the cost borne by doers following the law and increase opportunities for people to follow the law. 9 In other words, for the sake of smooth implementation of specific pubic policies, it is unwise to excessively impede people's daily life.

\section{B. Improve the Legislation Degree of Anti-terrorist Security Check}

The intensification of Anti-terrorist preventive security check in safe city strategy does not mean the neglect of liberty. In fact, security and liberty do not conflict. What people want to know is not that liberty is more important or more unimportant than security but that the damage of safety measures to liberty is more or less than the safety that it promotes. 10 Legalized ways must be used to make liberty and security reach new balance. It is also the aim of safe city strategy. In April 14, 2015, the Communist Party of China issued Opinions on Strengthening the Construction of Crime Prevention and Control System, in order to take strict precautions against violent terrorist attack on bus and subway through strengthening the security of public transport, the construction and daily management of civil defense, material defense and technical prevention, and improving and implementing the security check system. Article 9 of Counterterrorism Law of the People's Republic of China stipulates the obligation of individuals and units in assistance and coordination of anti-terrorism. Article 35 specifically stipulates the obligation of operation units in strengthening security check in urban public transport field. The above norms make preventive anti-terrorism security check legalized. However, the above norms are frame on the whole. It needs detailed system to make the whole security check procedure conform to the spirit of rule of law.

\section{CONCLUSION}

At present, violent terrorist activities are active in China We shoulder arduous Anti-terrorist task. According to terrorist attack aiming at bus in Xinjiang region and serious violent terrorist events happened in Kunming railway station and Golden Water Bridge in Beijing, it indicates terrorist attack also aims at urban public transport field in China. Public transport field is the hot spot and core of Anti-terrorist. The realization of security in public transport field will prevent most of the terrorist attack. Otherwise, it will reduce the sense of security of the public furthest. Therefore, in the construction of safe city strategy, we must draw experience and lessons from Anti-terrorist in international public transport field, reach consensus and strengthen preventive security check measures, in order to form benign urban safe strategy, prevent extreme terrorist attack and guarantee urban social security.

\section{REFERENCES}

[1] Ma Defeng: Safe City: Inspection on the Basis of Multi-dimensional Views, Urban Planning Forum, the First Issue of 2005

[2] Liu Mao, Zhang Qingsong: Urban Public Security: Theoretical Methods and Application, China Petrochemical Press 2014 Edition, page 6

[3] Wang Fazeng: Urban Crime Space, Southeast University Press 2012 Edition, page 29

[4] Zhang Hengchao: Research on Anti-terrorist Construction Planning in Urban Mass Transit Security, Journal of Fujian Police College, the First Issue of 2008

[5] Zang Jianguo: Discussion on Suicide Terrorist Crime, Southeast University Press 2013 Edition, page 141

[6] Yang Shu, Jiao Yiqiang: Research on Urban Anti-terrorist Security District Division and Grade, Journal of Lanzhou University (Social Sciences), the Second Issue in 2008

[7] [America] Richard Posner: Not a Suicide Pact: The Constitution in a Time of National Emergency, translated by Su Li, Peking University Press 2010 Edition, page 29

[8] Tong Zhiwei: Comparison and Reference between American "Safe City Plan" and Public Security Maintaining of Our Country, Journal of Beijing Police College, the First Issue of 2013

[9] Chen Mingxiang: The Science of Law and Policy, Yuanzhao Press Co., Ltd, 2011 Edition, page 175

[10] [America] Richard Posner: Not a Suicide Pact: The Constitution in a Time of National Emergency, translated by Su Li, Peking University Press 2010 Edition, page 29. 